\title{
CHOMSKY E A LINGUÍSTICA CARTESIANA
}

\section{Candice GLENDAY*}

RE SUM O: Este artigo tem por objetivo apresentar e examinar criticamente alguns dos principais argumentos fornecidos pelo linguista norte-americano Noam Chomsky, em favor da tese da origem inata de uma gramática universal, usualmente associada à tradição filosófica racionalista, como constituindo a única explicação possível das características específicas da linguagem humana e de sua aquisição, na mais tenra infância. Serão, por conseguinte, examinadas algumas críticas feitas por Thomas $\mathrm{N}$ agel à tese do assim chamado inatismo biológico de Chomsky e, ao final do artigo, será feita uma defesa dos argumentos de Chomsky em favor de sua tese inatista.

PALAVRA S-CHAVE : Inatismo biológico. Gramática universal. Linguagem. Racionalismo.

$\mathrm{Na}$ modernidade, o debate travado entre racionalistas e empiristas marcou o mundo filosófico. A pesar de dizerem respeito antes de tudo a problemas relativos à teoria do conhecimento, essas concepções determinaram também respostas opostas para problemas concernentes a outros ramos da filosofia, como a ética, a filosofia política, a estética etc., acabando por ter também reflexos importantes, bem mais tarde, no tratamento dispensado aos problemas linguísticos (ROBIN S, 1979, p. 88).

Como se sabe, uma tese característica dos filósofos racionalistas é aquela segundo a qual os seres humanos seriam possuidores de um

\footnotetext{
* Mestre em Cognição e Linguagem pela Universidade Estadual do Norte Fluminense Darcy Ribeiro, tradutora e professora de inglês na rede FAETEC.
} 
conhecimento não derivado da experiência e, sim, "anterior à experiência", também chamado de conhecimento a priori. Grosso modo, os racionalistas usavam a expressão "anterior à experiência" em dois sentidos. De um lado, a expressão "anterior à experiência" era tomada em sentido lógico, ou seja, designando a posse de um conhecimento válido independentemente da experiência, mas que precisaria do estímulo da experiência, até mesmo para que 0 sujeito cognoscente tomasse consciência dele. $\mathrm{Na}$ medida em que sua filosofia apresenta uma faceta racionalista, Immanuel Kant pode ser apresentado como um exemplo de concepção da anterioridade do conhecimento em sentido lógico. Essa concepção racionalista do conhecimento a priori procurava estar livre de premissas metafísicas, rejeitando veementemente a tese de uma origem inata desse conhecimento válido independentemente da experiência, posto que, à época, ele era facilmente associado com pressupostos metafísicos, como o da existência de Deus e da imortalidade da alma. ${ }^{1}$ De outro lado, em contraposição a isso, filósofos racionalistas como, por exemplo, Descartes e Leibniz, não viam problema algum em assumir semelhantes compromissos fortemente metafísicos e defenderam a tese do inatismo em sentido ontológico. A ssim, Descartes acreditava que a alma racional dispõe de um tesouro de "ideias" nela implantado desde sua criação por Deus, como a própria ideia de Deus e dos objetos matemáticos perfeitos, cujos conteúdos não podem ser encontrados em nenhuma experiência e, por isso mesmo, não necessitariam de nenhuma experiência para que o sujeito tomasse ciência delas. Porém, independentemente de assumirem ou não tais compromissos metafísicos, outra tese fundamental característica dos racionalistas é a de que o suposto estoque de conhecimento ou de ideias prévias e independentes da experiência determina de uma maneira necessária, ou seja, a priori, a forma pela qual os dados fornecidos pela experiência serão organizados, pensados e conhecidos.

Em contraposição a ambas as variantes do racionalismo, encontramos a concepção empirista, a qual teve sua origem em parte numa reação às ideias então predominantes, oriundas da Escolástica medieval. Assim, apesar das diferenças verificadas entre eles, empiristas como Bacon, Hobbes, Locke, Berkeley e Hume argumentavam que 0 aparato cognitivo do ser humano seria, originalmente, como uma tabula rasa, ou seja, que a mente humana seria como uma espécie de quadro em branco, no qual a experiência deixa marcas que seriam posteriormente elaboradas, de acordo com princípios

${ }^{1}$ Para uma detalhada discussão sobre os argumentos kantianos em favor da rejeição do inatismo, cf. o artigo de MARQUES, Ubirajara Rancan de Azevedo. 'Sobre o 'Inato' em Kant". Analytica, v.12, n.2, 2008. Disponível em www.analytica.inf.br. Acesso em jan. 2010. 
psicológicos de associação. 0 empirismo nega terminantemente que os seres humanos estejam de posse de qualquer conhecimento não originado da experiência, recusando de uma maneira ainda mais veemente que eles possam dispor de ideias inatas. Para o empirismo, o conhecimento deriva inteiramente das impressões sensoriais e das operações mentais, i.e., psicológicas, realizadas pela mente, por meio de abstração e de generalização indutiva exercida sobre os dados das impressões sensíveis. Ele também rejeita a ideia de um conhecimento que precederia a experiência, mesmo em sentido meramente lógico, ou seja, recusa completamente qualquer componente a priori determinante da forma do nosso conhecimento.

Concentrando nossa atenção agora especificamente na noção de ideias inatas ou de conhecimento inato, podemos dizer que, desde sua introdução por Platão, no diálogo M ênon, ela se tornou centro de debates sérios, depois foi praticamente abandonada, para ser retomada, contemporaneamente, de modo totalmente novo e surpreendente, a partir de argumentos provenientes de outras áreas do saber, mais exatamente, da linguística e da psicologia desenvolvidas nos trabal hos do linguista norte-americano Noam Chomsky. Chomsky defende a tese inatista como única explicação possível para dar conta de certas características específicas da linguagem humana e de sua aquisição, não admitindo categoricamente que o behaviorismo, sucedâneo do empirismo, possa dar conta adequadamente do fenômeno da linguagem. Entretanto, Chomsky está ciente dos problemas e das objeções ligadas à tese inatista. Pois, afinal, que conceito estaria sendo veiculado pela palavra "inatismo"? Os defensores dessa tese, ao longo da história, pareceram tomála por algo não problemático, explicando-a por sinônimos como "nãoaprendido", "congênito", i.e., "algo com o que já se nasce". Diante disso, os opositores argumentam que não conseguem discernir nenhum sentido interessante para essa doutrina, até porque os empiristas nunca negaram que haja, nos seres humanos, algumas capacidades que podem ser consideradas inatas ou não-aprendidas, o que pode ser empírica e trivialmente constatado, por exemplo, no fato de todos os homens nascerem "sabendo" respirar, mamar, digerir alimentos etc. A nalogamente, é um fato trivial que somente seres humanos apresentam a capacidade de aprender uma língua e que, portanto, a capacidade de aprender uma língua teria de ser considerada como algo inato ao ser humano.

De fato, se a introdução da noção de inatismo deve se revelar um instrumento relevante para a compreensão do fenômeno da linguagem humana, tem de ser possível apresentá-la como uma concepção interessante sobre os mecanismos cognitivos humanos, mais especificamente, sobre os mecanismos de aquisição da linguagem. Pois, se a tese tivesse como consequência que determinadas atividades fisiológicas do ser humano, como, 
por exemplo, a digestão, pudessem ser igualmente reconduzidas a uma base inata, o conceito de inatismo deixaria de ser relevante para dar conta de um processo especificamente humano, como Chomsky considera ser o caso da linguagem humana. $\mathrm{Na}$ verdade, estamos interessados em algo de ordem de conhecimento inato. Com esse objetivo, procederemos a uma breve exposição de algumas características da tese do inatismo, em Chomsky, e de algumas objeções feitas a ela por Thomas Nagel, às quais procuraremos responder, ao fim deste artigo.

A intuição fundamental que está na base da linguística desenvolvida por Chomsky e que, em suas próprias palavras, faz com que ela esteja alinhada com o que ele chama de "linguísticas cartesianas", é a suposição de que "as características gerais da estrutura gramatical são comuns a todas as línguas e refletem determinadas propriedades da mente" (CHOMSKY, 2002, p. 94). De acordo com isso, uma análise da estrutura gramatical profunda das línguas particulares levaria ao estabelecimento da "forma da linguagem", em geral, a qual conteria estruturas universais e invariáveis que imporiam limites às possibilidades de variação, na multiplicidade das línguas particulares encontradas no tempo e no espaço. Ainda conforme essa tradição racionalista, não é razoável supor que essas estruturas universais viriam a ser aprendidas pelos falantes, quando postos em contato com as línguas particulares, por ocasião do seu aprendizado. Pelo contrário, essas estruturas universais tornariam primeiramente possível o aprendizado de toda e qualquer língua particular, na medida em que dotariam os aprendizes de princípios organizadores dos dados linguísticos a que estão expostos. A lém disso, pelo fato de tais estruturas e princípios de organização estarem universalmente presentes e não serem extraídos das experiências com os dados das línguas particulares, Chomsky conclui que eles constituem parte da própria estrutura mental dos falantes, como uma propriedade inata a eles. Na perspectiva de Chomsky, essa explicação seria a única que poderia dar conta do fato prodigioso da aquisição de uma língua particular, num tempo relativamente curto e independentemente do grau de inteligência dos aprendizes.

$\mathrm{Na}$ verdade, uma das razões que fizeram com que Chomsky viesse a ressuscitar a tese inatista, na contemporaneidade, foi a assim chamada criatividade da linguagem. De fato, uma das características mais marcantes das línguas naturais humanas, que, contudo, passou simplesmente despercebida ou foi negligenciada pela tradição empirista, é a sua "abertura ao infinito", a qual dota os falantes e usuários da capacidade de produzir e 
compreender um número infinito de frases que eles jamais ouviram antes e que talvez jamais tenham sido proferidas por alguém antes, de uma maneira sempre apropriada às situações (CHOMSKY, 2002, p. 51). Um ponto importante da argumentação de Chomsky é que esse domínio criativo da linguagem é uma característica única dos seres humanos, sendo específico da espécie. É verdade que, por exemplo, abelhas são capazes de comunicar a distância entre a fonte do néctar e a colmeia por meio da diferença de intensidade de seus movimentos corporais, em que o parâmetro da intensidade dos movimentos está sujeito a uma variação contínua e infinita (LYONS, 1975, p. 25). Também na linguagem humana esse tipo de variação de intensidade está presente no modo como podemos pronunciar uma palavra. Porém, a criatividade em questão, unicamente presente na linguagem humana, não diz respeito à possibilidade de variação contínua dos parâmetros de um sinal, no sistema de comunicação, mas antes às infinitas possibilidades de combinação dos elementos discretos, de acordo com regras que constituem o sistema.

A criatividade assim concebida impõe desafios específicos para uma teoria psicológica da linguagem e da sua aquisição, uma vez que é a complexidade estrutural específica da linguagem humana, principalmente no nível sintático, que possibilita essa criatividade. Mas é difícil aceitar que essa estrutura extremamente complexa possa ser adquirida com base nos conhecidos mecanismos de estímulo e resposta, como alegam os behavioristas, tendo em vista que o aprendizado de uma língua é algo extremamente caótico e fragmentário. Não há como supor que uma criança proceda a generalizações feitas a partir de dados tão caóticos e desordenados. Observe-se também que o aprendizado ocorre na mais tenra infância, antes que muitas outras faculdades intelectuais tenham se desenvolvido, e não depende de fatores sociais e econômicos especiais. Uma criança pobre aprender português na favela onde vive, sem necessidade de ensino formal, indo à escola somente para aprender a ler e a escrever. Com base em semelhantes observações, Chomsky conclui que o que torna possível o aprendizado de algo tão complexo, como uma língua natural, é o fato de a criança dispor de uma gramática universal, inscrita na sua própria herança genética, com base na qual ela constrói nada menos que uma teoria das regras gramaticais da língua a que está exposta. Desse modo, Chomsky propõe e defende um inatismo biológico.

A defesa da presença de estruturas e princípios universais organizadores dos dados linguísticos recebidos pelos aprendizes de uma língua particular é um dos traços que fazem com que Chomsky seja aproximado do racionalismo e da tese da existência de conhecimento a priori. Contudo, é preciso fazer algumas qualificações aqui, de modo a salientar 
uma especificidade da concepção do que poderíamos chamar de a priori linguístico, em Chomsky.

Desde Kant, costuma-se apontar para a validade necessária e universal de um princípio ou enunciado, como marcas características de sua origem ou validade a priori. De fato, na Crítica da Razão Pura (Introdução, B 3-4), Kant afirma que os conceitos de necessidade e de universalidade podem ser usados, de uma maneira intercambiável e logicamente equivalente, como critérios do estabelecimento da validade a priori de um juízo. Assim, o juízo "Todos os corpos são extensos" é universalmente válido, permitindo derivar imediatamente o seguinte juízo: "Para todo x, se x é um corpo, então, necessariamente, $x$ é extenso".

Ora, a concepção dos universais linguísticos presentes a priori na seleção e organização dos dados linguísticos, em Chomsky, apresenta uma importante diferença, comparada à concepção do a priori, em Kant ${ }^{2}$. Com efeito, segundo Chomsky, os universais linguísticos não são necessariamente encontrados em toda e qualquer língua particular (CHOM SKY, 2002, p. 136). Ou seja, para Chomsky, universalidade não é intercambiável com necessidade. Como observa Lyons, nesse aspecto, Chomsky pode ser aproximado do linguista russo Roman J akobson (LYONS, 1975, p. 98), pois ambos acreditam na existência de determinadas unidades fonológicas, sintáticas e até mesmo semânticas, universais, mas não no sentido de estarem necessariamente presentes em toda e qualquer língua particular. Assim, no nível fonológico, é possível mostrar que há uma série fixa de até vinte características distintivas, como, por exemplo, características de voicing ou pares mínimos presentes, por exemplo, na distinção entre " $p$ " e " $b$ " ou " $t$ " $\mathrm{e}$ " $d$ ", tornando diferente a pronúncia das palavras "pomba" e "bomba" ou "tato" e "dado". Tomadas em seu conjunto, semelhantes características constituem uma "fonética universal". Porém, isso não significa que características como as apresentadas acima terão de ser encontradas nos fonemas de toda e qualquer língua particular. A universalidade em questão significa antes que essas características fixam todas as combinações possíveis, por assim dizer, postas à disposição para formar e constituir as línguas particulares. Quer dizer, cada língua particular se constitui como

\footnotetext{
${ }^{2} \mathrm{Na}$ verdade, é digno de nota que o próprio Chomsky tenha concluído seu "survey" ou "levantamento" da linguística de inspiração racionalista lamentando "não ter sequer mencionado ou ter discutido apenas inadequadamente figuras maiores dessa tradição, como Kant" (CHOMSKY, 2002, p. 104). De fato, um estudo comparativo das duas concepções seria muito interessante, pois outra importante diferença entre Kant e Chomsky consiste em que o primeiro sustenta igualmente a existência de conhecimento a priori, recusando, porém, explicitamente, que ele seja de origem inata (cf., a esse respeito, Crítica da razão pura, B 167-168).
} 
uma seleção de possibilidades combinatórias estabelecidas, seja pelo que Chomsky chama de "universais substantivos", i.e., a série de unidades ou elementos fonológicos, sintáticos e semânticos, seja pelo que ele chama de "universais formais", i.e., a série de princípios gerais transformacionais que determinam a forma das regras e do modo de operar com ela, nas gramáticas das línguas particulares (CHOM SKY, 1965, p. 27-30). Eis por que Chomsky vai se referir aos universais linguísticos como fornecedores de "princípios e parâmetros", diante dos quais cada língua particular se constitui como uma seleção determinada no interior de possibilidades combinatórias postas à disposição (CHOM SKY, 1995, p. 13-129). Segundo Chomsky, esses parâmetros universais e inatos são utilizados pela criança aprendiz de uma língua como princípios de seleção dos inputs por ela recebidos.

Ainda em concordância com a tradição racionalista, Chomsky também sustenta que esses universais linguísticos antecipadamente presentes no aprendiz necessitam de experiência adequada, a saber, os proferimentos feitos nas línguas particulares, para serem ativados ou postos em funcionamento, pois, do contrário, permanecem em estado latente ou mesmo inconsciente. Nesse sentido, Chomsky estaria ao lado daqueles que sustentam que as línguas humanas são um empreendimento de caráter necessariamente social e intersubjetivo, concordando com a tese de que o "menino lobo" não teria podido desenvolver uma linguagem. Contudo, diferentemente do que concluíram os empiristas, disso não se segue que aqueles princípios organizadores resultem eles próprios da experiência, sendo antes princípios sem os quais não ocorre absolutamente nenhuma experiência (CHOM SKY, 2002, p. 96). A lém disso, se é verdade que, ao serem estimulados e postos em funcionamento pelos inputs linguísticos apropriados, esses princípios saem do estado de latência, o seu funcionamento acontece sem intervenção consciente, por parte do indivíduo aprendiz de uma língua particular. Nesse sentido, segundo Chomsky, esse conjunto de princípios atua de uma maneira que pode ser antes aproximada ao modo de funcionamento de um instinto natural, do que ao modo de funcionamento da faculdade da razão, que, pelo menos na tradição cartesiana, é identificada à própria consciência (CHOMSKY, 2002, p. 97). Essa é uma importante diferença entre Chomsky e a tradição a que ele próprio se filia, e que caracteriza o seu inatismo biológico. É por essa razão que Chomsky sustenta que a tarefa do linguista consiste na explicitação consciente desses princípios, os quais estão na base da aquisição de uma língua, para o que ele conta com a possibilidade de reconhecimento, por parte do falante, quanto à adequação explicativa dos princípios explicitados (CHOM SKY, 1965, p. 24-5).

Contudo, apesar de reconhecer a necessidade de estimulação apropriada por inputs linguísticos, a abordagem racionalista não hesita em conceder um papel seriamente restrito e limitado ao condicionamento e à 
instrução explícita no processo de aprendizagem de uma língua, em contraposição à abordagem empirista e às abordagens behavioristas contemporâneas. Aliás, a esse respeito, é interessante confrontar brevemente o que pensa um autor como Ludwig Wittgenstein, a respeito da situação inicial em que se encontra o aprendiz de uma língua, com o que pensa a tradição racionalista. Wittgenstein constitui um caso bastante interessante, porque, apesar de seus reiterados esforços no sentido de não ser confundido com o behaviorismo semântico (WITTGENSTEIN, 1975, § 244), Chomsky não hesita em se referir ao seu modo de explicar o aprendizado de uma língua como estando muito próximo daquele defendido por Bloomfield. E, de fato, no § 32 das Investigações Filosóficas, Wittgenstein tece a seguinte crítica à assim chamada teoria agostiniana da linguagem, da qual podemos retirar elementos para contrastar com o que pensam os racionalistas sobre a situação original em que se encontra o aprendiz de uma língua materna. Segundo Wittgenstein, (1975, p. 23)

[...] alguém que chega a um país estrangeiro aprenderá a língua dos nativos algumas vezes a partir de definições ostensivas que eles the fornecem; e, freqüentemente, ele terá de 'adivinhar' o significado dessas definições, algumas vezes corretamente, algumas vezes incorretamente. E, agora, penso, podemos dizer: Agostinho descreve o aprendizado da linguagem humana como se a criança chegasse a um país estrangeiro e não compreendesse a língua do país; ou seja, como se a criança já tivesse uma língua, só não aquela.

O que Wittgenstein chama de "definição ostensiva" é um modo de explicar o significado de uma palavra apontando para ou exibindo a coisa ou aspecto da coisa que é designado pela palavra que se pretende explicar. Nos parágrafos iniciais do Blue Book, uma obra anterior às Investigações, Wittgenstein já havia desenvolvido críticas à noção de definição ostensiva, salientando as dificuldades de se ensinar uma palavra fictícia, a palavra "tove", apontando para uma caneta sobre uma mesa, já que, de acordo com ele, 0 aprendiz poderia ser levado a pensar que "tove" designa não o objeto, a caneta, mas, sim, por exemplo, a sua cor ou a sua posição sobre a mesa, e assim por diante (WITTGENSTEIN, 1987, p.2). É por essa razão que, na passagem das Investigações acima citada, Wittgenstein afirma que 0 aprendiz terá de "adivinhar" o que é designado pelas definições ostensivas dadas pelos nativos da língua estrangeira, algumas vezes corretamente, outras vezes incorretamente. Assim, o sentido da crítica tecida por Wittgenstein à concepção agostiniana da linguagem, na passagem citada, é o seguinte: A gostinho conceberia o aprendizado de uma primeira língua como se fosse algo análogo ao de uma segunda língua, como se, ao chegar 
ao mundo, a criança de alguma forma já dispusesse de todas as distinções conceituais e categoriais que lhe permitiriam depreender o que está sendo visado, a cada vez, pelo professor que aponta para um objeto, bastando para isso apenas que o último chame a atenção do aprendiz de uma maneira adequada. Ora, está implícito, na mesma passagem, que a criança, na concepção de Wittgenstein, é, originalmente, no que tange a essas distinções categoriais, como uma tabula rasa. Por isso mesmo, ela sequer poderia adivinhar o que está sendo designado, por ocasião de uma definição ostensiva, por mais que o professor se esforçasse em conduzir adequadamente a atenção da criança, diferentemente da situação de quem aprende uma segunda língua e que já traz essas distinções, aprendidas juntamente com a língua materna.

Contra semelhantes concepções behavioristas, que, por assim dizer, "subestimam" a capacidade das crianças aprendizes, Chomsky argumenta que elas "não assentam numa observação dos fatos livre de preconceitos, mas, sim, em suposições a priori acerca do que elas acreditam que tenha de ocorrer" (CHOM SKY, 2002, p. 138) ${ }^{3}$, citando em seu apoio uma passagem de Cordemoy, cujo conteúdo contrasta fortemente com o daquela passagem das Investigações de Wittgenstein.

Quaisquer que sejam as dificuldades que encontramos ao ensinar-Ihes algumas coisas, descobrimos, freqüentemente, que eles sabem o nome de mil outras coisas que nós não pretendíamos mostrar-lhes; e, o que é mais surpreendente, vemos que, quando atingem os dois ou três anos de idade, eles são capazes de distinguir o nome que damos a uma coisa, pela mera força de sua atenção, em todas as construções que usamos para falar da coisa. (apud CHOM SKY, 2002, p. 138).

Tal é o sentido geral das teorias da aquisição da linguagem de orientação racionalista. Observamos, frequentemente, que as crianças sabem mais do que inicialmente esperaríamos delas, de modo que, "pela mera força de sua atenção", desde que convenientemente dirigida pelo professor, podem depreender o que estamos visando com nossas explicações. Desse modo, Chomsky sustentaria contra Wittgenstein que, em certo sentido, a criança já chega ao mundo sabendo uma língua, i.e., uma linguagem universal, não apenas aquela língua particular da localidade em que nasceu, e que 0 conhecimento prévio daquela linguagem universal é fundamental para que

\footnotetext{
${ }^{3}$ Eis por que nos sentimos inclinados a concordar com Wolfgang Stegmüller (1976, p. 15), quando ele afirma que, "no entender do sistemático Chomsky, [as considerações tecidas por Wittgenstein] eram mais ou menos diletantes".
} 
venham a ser bem-sucedidas todas as tentativas empreendidas pelos adultos, no sentido de lhe "ensinar" a língua falada naquela localidade.

Assim, se é verdade que inputs externos são necessários para ativar e estimular o funcionamento dos princípios inatos, esses inputs não determinam eles próprios a forma do que é adquirido, nem o aprendiz de uma língua deve ser comparado a uma tabula rasa, a um passivo receptor de dados linguísticos. Nesse ponto, devemos assinalar que, apesar das constantes referências a Descartes, é antes em Leibniz que Chomsky encontra sua inspiração para conceber seu inatismo, rejeitar o empirismo e pensar a relação entre os princípios inatos da gramática universal e as regras de uma língua particular adquirida, como podemos notar na seguinte passagem (LEIBNIZ, 1996, p. xvii-xviii):

Por isso, servi-me antes da comparação com uma pedra de mármore com veias, e não com uma pedra de mármore completamente lisa ou com tábuas vazias, i.e. com isso que os filósofos chamam de tabula rasa. Pois se as almas se assemelhassem a essas tábuas vazias, as verdades estariam em nós como a figura de Hércules está no mármore, quando esse mármore é completamente indiferente à recepção dessa figura ou à de qualquer outra. Mas se houvesse veias na pedra que indicassem a figura de Hércules em lugar de qualquer outra figura, essa pedra seria mais determinada com relação a isso, e Hércules estaria nela, em certo sentido, como algo inato, ainda que fosse necessário algum trabalho para descobrir essas veias, para limpá-las mediante polimento e para livrálas de tudo aquilo que impede que apareçam claramente. E é assim que as ideias e as verdades nos são inatas, como inclinações, como disposições, como hábitos ou potencialidades naturais, e não como ações, ainda que essas potencialidades sejam sempre acompanhadas de al gumas ações, frequentemente não percebidas, que Ihes correspondem.

Nessa perspectiva, segundo Chomsky, em certo sentido, uma língua não pode ser propriamente ensinada, mas, sim, somente despertada na mente do falante, pois, exprimindo sua concordância com Humboldt, outro "linguista cartesiano", Chomsky também sustenta que as línguas "são autocriações (Selbstschöpfungen) dos indivíduos falantes" - e complementa com a citação de outra passagem de uma obra do estudioso da linguagem alemão (CHOM SKY, 2002, p. 97).

0 aprendizado da linguagem por parte das crianças não é um mero distribuir $^{4}$ palavras a serem depositadas na memória e reproduzidas

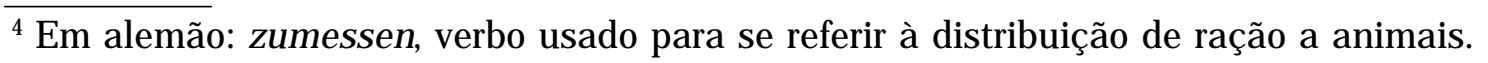


mecanicamente pelos lábios, mas um amadurecimento (ein Wachsen) da capacidade lingüística com a idade e com a prática. Que nas crianças não haja um mecânico aprendizado da linguagem, mas um desenvolvimento da faculdade lingüística é também provado pelo fato de que, uma vez que as mais importantes capacidades humanas exigem um determinado período da vida para seu desenvolvimento, todas as crianças, colocadas nas mais diversas circunstâncias, falam e compreendem mais ou menos com a mesma idade, com uma pequena variação dentro de um breve lapso de tempo.

Isso significa que a aquisição de uma língua é um processo de maturação de capacidades regidas por princípios internos ao aprendiz, desde que ele esteja exposto a condições externas apropriadas. A forma da língua que é assim adquirida não é determinada pelo que é recebido vindo de fora, mas por fatores e princípios internos e inatos ao falante. $E$, como esses princípios internos são específicos da espécie humana, terá de haver uma correspondência fundamental entre todas as línguas encontradas no tempo e no espaço. Em última análise, isso explica igualmente por que uma criança nascida no Brasil pode vir a aprender o japonês como língua materna, se levada para of apão na idade apropriada, e vice-versa, ao passo que, segundo Chomsky, um hipotético marciano não poderia aprender nenhuma das línguas naturais humanas, visto que a forma geral dessas línguas é específica de nossa espécie.

II

Para estabelecer uma discussão crítica fecunda da tese inatista em Chomsky, foi escolhido um artigo escrito por Thomas Nagel (1974). A escolha desse autor se deveu a duas razões. Em primeiro lugar, porque se trata de um autor contemporâneo dos mais brilhantes, na Filosofia. Em segundo lugar, porque se trata de um intérprete simpático a Chomsky e que partilha com ele de alguns importantes pressupostos sobre a investigação da linguagem, como, por exemplo, o valor da perspectiva internalista sobre a linguagem. A ssim sendo, diferentemente de críticas externas provenientes de autores que antecipadamente sabemos serem antipáticos a Chomsky, podemos esperar encontrar em Nagel argumentos tecidos por alguém que se coloca dentro da perspectiva do próprio autor a ser criticado e que, por isso mesmo, serão muito mais relevantes para nós.

Thomas Nagel investiga as implicações epistemológicas da teoria linguística de Chomsky, sobretudo no que diz respeito à tese de um conhecimento a priori inato por parte do aprendiz de uma língua. A pergunta 
que orienta seu pequeno artigo é a seguinte (NAGEL, 1974, p. 219-220): em que sentido a contribuição inicial feita pelo organismo que está adquirindo uma linguagem deve ser descrita em termos de conhecimento? Em que sentido é possível atribuir à criança aprendiz da linguagem um conhecimento, por exemplo, de estruturas sintáticas? Buscando responder a essa questão, Nagel examina, inicialmente, o que ele próprio considera ser um mau argumento, geralmente apresentado como evidência para responder negativamente a essa mesma questão.

Em linhas gerais, o mau argumento pode ser exposto como se segue. Costuma-se alegar que a posição assumida por Chomsky o levaria a se comprometer com a tese de que haveria igualmente um conhecimento inato, por parte do ser humano, no que concerne, por exemplo, ao seu sistema digestivo. Com efeito, mesmo sem ter sido previamente treinada, instruída ou informada, a criança é capaz de ajustar o meio ambiente químico em seu estômago, de modo a selecionar entre o que deve ser absorvido e o que deve ser rejeitado. Ou seja, também no processo de digestão estariam presentes, desde o início e sem terem sido aprendidos, princípios de seleção de inputs recebidos, resultando em determinados outputs, de uma maneira que seria perfeitamente análoga àquela descrita por Chomsky, no processo de seleção dos inputs feita pelo aprendiz da linguagem.

E o paralelo entre a digestão e a linguagem poderia ser levado ainda mais longe, se considerarmos que, em ambos os casos, não é preciso haver consciência explícita dos princípios ou regras que regulam ambas as atividades, nem na criança, nem no adulto, embora este último possa estudar esses princípios, os quais constituem a fisiologia da digestão ou a gramática de uma língua, o que, contudo, não é relevante para as próprias atividades.

Da possibilidade de estabelecimento de tal paralelo entre a atividade da digestão e a aprendizagem de uma linguagem, os críticos concluem que ou bem tem de haver a interferência de um conhecimento inato igualmente nos dois casos, ou bem não há sentido, absolutamente, em se falar de conhecimento inato, nos dois casos. Pondo o peso do argumento no processo de digestão, levado a cabo até mesmo por animais, os críticos de Chomsky tendem para a segunda alternativa e sustentam que seria mais adequado falar na presença de capacidades inatas, a saber, da capacidade de discriminar entre elementos presentes nos alimentos que podem ser assimilados pelo organismo e da capacidade de adquirir o domínio de línguas naturais dotadas de um certo tipo de estrutura - e não, de modo algum, na presença de conhecimento inato.

Isso posto, Nagel procede a uma avaliação crítica do argumento acima, mostrando que ele apresenta uma falha de princípio, que reside no fato de 
ele ignorar a diferença essencial que há nas operações e atividades comparadas (N A GEL, 1974, p. 221). Com efeito, no caso da digestão, não se pode falar em ações executadas por parte de um sujeito ou indivíduo (ele está antes sujeito a essas operações, que ocorrem no interior de seu corpo), nem os dados sobre os quais se realizam tais operações precisam ser trazidos à consciência desse mesmo indivíduo. Em contrapartida, no caso da linguagem, os dados (os inputs linguísticos) têm de ser conscientemente apreendidos pelo indivíduo, de sorte que o resultado desse processo se manifesta na capacidade de falar e de compreender sentenças (os outputs linguísticos), ou seja, em ações conscientes.

Além disso, e ainda mais importante, o exercício da capacidade linguística envolve a produção de crenças por parte do aprendiz (NAGEL, 1974, p. 221), por exemplo, com relação ao fato de que uma determinada combinação de palavras forma uma sentença da linguagem (o que pode ser facilmente verificado, se apresentarmos a uma criança que já domina algum português a frase: (“*dormindo a está boneca"). ${ }^{5}$ Em suma, nem todos os métodos ou processos de seleção e discriminação supõem a formação ou a atribuição de crenças, e somente os que as supõem fornecem evidência para se introduzir conceitos epistemológicos, na sua descrição, quer dizer, para se falar, coerentemente, de conhecimento. $\mathrm{E}$ o fenômeno da linguagem se enquadra no último caso, ao passo que a digestão não se enquadra.

Contudo, o próprio Nagel admite que o essencial na avaliação crítica da proposta chomskyana é determinar se conceitos cognitivos, como o de conhecimento ou o de crença, podem ser adequadamente introduzidos, em primeiro lugar, na descrição da capacidade (supostamente inata) de adquirir a capacidade de falar uma língua natural, e, em segundo lugar, na descrição da capacidade de falar uma língua natural, considerada de uma maneira geral (NAGEL, 1974, p. 222). Ele começa pela segunda questão e, em nossa exposição, faremos o mesmo.

A esse respeito, é interessante pôr em linha de conta a comparação que M ichael Dummett (1978, p. 1-15) estabelece entre saber nadar e saber falar uma língua. Com efeito, saber nadar e saber falar uma língua são, no fundo, saberes ou conhecimentos práticos que se mostram no exercício de capacidades ou habilidades práticas. ${ }^{6}$ A questão é se o conhecimento prático envolvido nesses casos explica a habilidade prática ou se o conhecimento

\footnotetext{
${ }^{5}$ Em linguística, é uma prática usual antepor o símbolo $\left(^{*}\right)$ para designar sequências de sons ou de palavras, que, de acordo com as regras dos níveis descritos mencionados, estão incorretamente combinados.

${ }^{6}$ Exatamente por isso se pode dizer "I can swim" ou "I can speak English", em lugar de "I know how to swim" ou de "I know how to speak English".
} 
prático se reduz inteiramente às ações em que se manifesta a habilidade prática. Se a última alternativa for o caso ,no que tange à capacidade de falar uma língua natural particular, introduzir a expressão "conhecimento" nesse contexto será, por consequência, inútil e desnecessário.

Todavia, existe uma grande diferença entre saber nadar e saber falar uma língua, a qual reside no fato de que o exercício da capacidade de falar é um processo que tem de ser considerado como um processo consciente, num sentido em que o exercício do saber nadar não o é. Na verdade, podemos conceber que uma pessoa seja jogada na água e se dê conta de que está nadando, mesmo sem saber o que está fazendo, mas não é concebível que uma pessoa não educada, por exemplo, em espanhol, e que seja levada para um país de língua espanhola venha a se dar conta, miraculosamente, de que está falando espanhol, mesmo sem saber o que está fazendo. Desse modo, capacidades ou habilidades práticas não são todas iguais. No caso da habilidade de falar uma língua, a pessoa em questão tem de saber o que está fazendo e, por conseguinte, falar de "conhecimento" nesse contexto é plenamente justificável.

No entanto, temos de admitir que há diferentes graus na consciência ou no conhecimento que acompanha as ações em que se manifesta a habilidade prática de uma pessoa. Assim, num extremo da escala, há aquelas ações ou operações que são executadas acompanhadas do saber ou conhecimento explícito do que se está fazendo, por exemplo, quando obedecemos às instruções de uma receita de bolo. No outro extremo, há aquelas operações ou habilidades que são exercidas pela pessoa, sem que ela tenha a menor consciência do que está fazendo e, mesmo quando ela é chamada a refletir sobre o que está fazendo, é incapaz de explicar aos outros, como, por exemplo, o saber nadar ou andar de bicicleta. Nesses casos, 0 "saber como" se reduz inteiramente ao "poder fazer". Por fim, há também os casos intermediários, nos quais a pessoa pode se declarar inicialmente incapaz de formular, para si ou para os demais, os princípios que regem sua habilidade prática, mas pode vir a reconhecer posteriormente a correção de enunciados feitos por uma outra pessoa a respeito desses princípios. Nesse caso, podemos dizer com toda propriedade que a pessoa em questão sabe que algo é o caso, que ela (re)conhece a correção de certas proposições relativas aos princípios que regem suas operações, só que esse saber ou conhecimento é implícito, podendo, contudo, ser obtido dela, quando convenientemente indagada.

Dessa forma, voltando à segunda questão formulada por Nagel, temos de concluir que a capacidade geral de falar uma língua, manifestada por um indivíduo falante ao produzir uma série de performances linguísticas 
particulares, cada uma das quais, de acordo com o que foi dito acima, pode ser perfeitamente descrita como uma instância de conhecimento, tem de ser ela própria também descrita em termos de conhecimento. Naturalmente, tratase de um conhecimento implícito, que no mais das vezes não é formulado pelo próprio falante, mas que efetivamente regula as performances particulares e que, uma vez apresentado ao último, é por ele reconhecido como estando na base do exercício de sua capacidade de falar a língua em questão.

É importante acentuar que o falante de uma língua alcança o reconhecimento da relação entre as regras gramaticais, quando estas Ihe são apresentadas, e a sua performance linguística quotidiana não como resultado de uma mera observação de suas próprias reações e comportamentos externos, como se fosse algo exterior a ele próprio, mas como algo que provém, por assim dizer, do seu interior. Nesse sentido, um falante reconhece a relação entre as regras gerais de uma língua e suas performances particulares de um modo que se assemelha ao reconhecimento, por parte do paciente, da existência de uma relação interna entre suas patologias psíquicas e as situações que as geraram, quando as últimas Ihe são trazidas à consciência pelo psicanalista (NAGEL, 1974, p. 222-223).

Voltando, agora, à primeira e mais fundamental questão acima formulada: será que teríamos de caracterizar, como uma instância ainda mais geral de conhecimento, a capacidade geral de adquirir outras capacidades, que são elas próprias instâncias de conhecimento mais particulares? Ora, para que o nível de aquisição de uma língua possa ser caracterizado por conceitos cognitivos e por uma atribuição de um tipo de conhecimento ao falante, bastaria, a parentemente, poder repetir para o nível da aquisição o raciocínio que se mostrou válido para a capacidade de exercício de uma língua natural. Em outras palavras, uma vez explicitamente formulados os universais linguísticos, como as regras transformacionais, que, segundo Chomsky, regulam a aquisição originária de uma língua natural, teria de ser possível dizer que o falante poderia ser levado ao reconhecimento de que tais universais estavam presentes na situação de aprendizagem e efetivamente operando, no processo de seleção dos inputs. Ou seja, os princípios presentes no nível da aquisição da linguagem deveriam ser também acessíveis à perspectiva internalista, para poderem ser caracterizados como envolvendo um tipo de saber ou conhecimento.

Entretanto, conforme Nagel, pelo menos a julgar pelas declarações feitas por Chomsky, o que este último chama de "adequação explanatória", quer dizer, a exigência de confirmação por parte do linguista de que as regras transformacionais formuladas são efetivamente aquelas que presidem à seleção dos inputs não implica o assentimento e reconhecimento, por parte 
do próprio falante. Em suma, para o linguista, que faz uma teoria como qualquer outra, seria suficiente que as regras que ele formula de um ponto de vista externo se adequem aos dados a serem explicados, no caso, os que constituem o aprendizado de uma língua, como a melhor explicação para eles. Diante disso, Thomas Nagel declara não se sentir confortável para empregar conceitos cognitivos na descrição daquela capacidade inata de adquirir conhecimento linguístico, visto que nem toda capacidade inata de adquirir conhecimento tem de ser ela própria caracterizada como uma instância de conhecimento, por mais complexa que seja a descrição de sua estrutura, como, de acordo com a linguística, parece ser a descrição da estrutura da capacidade de adquirir conhecimento de uma língua natural particular (p. 224).

Na sequência do texto, Nagel passa a considerar a questão acerca do sentido de descrever, em termos de conceitos cognitivos, a capacidade inata de aprender uma linguagem, agora a partir de outra condição geralmente ligada à atribuição de conhecimento, a saber, a condição de justificação (p. 225). Ora, sem dificuldade, podemos admitir a presença de crenças inatas ou de uma tendência a formar determinadas crenças, diante de um input externo mínimo. Entretanto, isso ainda não constitui base suficiente para se falar em conhecimento com toda propriedade, pois nem toda crença que tenhamos inclinação a formar é por isso mesmo justificada, mesmo que essa crença seja verdadeira.

Observemos, por exemplo, uma situação hipotética, na qual uma pessoa tem um talento inato, mas que lhe é próprio enquanto indivíduo, para estabelecer resultados de cálculos matemáticos ou para aplicar às coisas o nome correto, sem que isso envolva reflexão, cálculo ou aprendizado. Ora, esse fictício talento só se tornaria confiável, e isso aos olhos da própria pessoa dele dotada, na medida em que os resultados a que chega se conformarem e concordarem com os resultados a que chegam as pessoas em geral, quando efetuam cálculos ou procedem à aplicação de nomes de uma maneira refletida, consciente e calculada. Ou seja, para ser considerado como algo pelo menos próximo de conhecimento, aquele suposto talento teria de ter a correção de seus resultados confirmada por uma instância objetiva e independente. Em suma, não é pelo mero fato de ser um talento ou propensão natural de um indivíduo, que esse talento obtém sua justificação e pode ser aproximado de algo da ordem do conhecimento (p. 225-226).

A situação proposta por Chomsky, visando a explicar a aquisição da linguagem, difere da acima descrita, pelo fato de se tratar de um talento ou capacidade natural e inato, partilhado pelos seres humanos em geral, mais exatamente, de um talento universalmente compartilhado. Seria justamente em virtude dessa capacidade que todos os falantes do português, por exemplo, acabam chegando a uma concordância geral no emprego dessa 
língua, em conformidade com certas regras gramaticais, de uma maneira natural, não-refletida, não-premeditada e não-calculada. Contudo, embora se trate aqui de um talento ou propensão supostamente compartilhado por todos os indivíduos falantes, também, nesse caso, o mero fato de haver uma tendência natural para chegar a determinadas regras da linguagem não assegura a sua justificação, do mesmo modo que aquela fictícia propensão ou talento individual para obter resultados corretos em cálculos matemáticos não assegurava a sua justificação. A ssim, quando o indivíduo sabe que suas próprias intuições e produções linguísticas estão em conformidade com as intuições linguísticas de outros falantes de sua linguagem, só então ele estará em posição de considerar que aquela sua tendência inata fornece uma forte evidência para concluir que suas próprias intuições são corretas. Diante disso, Nagel (1974, p. 226) sustenta que

\begin{abstract}
[...] a tendência inata universal a alcançar determinadas regras é suficiente, no caso da linguagem, para assegurar a correção das intuições de um falante individual. M as cada indivíduo necessita ainda saber que ele está em conformidade com a tendência universal, para saber que suas intuições lingüísticas estão corretas. E isso é uma questão que está aberta à investigação empírica.
\end{abstract}

Nagel termina concluindo que, considerada agora do ponto de vista da justificação, o que se pode depreender da posição sustentada por Chomsky é que ela não exprime uma autêntica tese sobre a existência de um conhecimento a priori (inato), mas, no máximo, de uma propensão ou tendência a formar determinadas crenças sobre as regras de uma língua, tendência essa que inclui uma outra tendência natural a supor que os outros formarão as mesmas regras. Embora não possam ser caracterizadas, em termos de conceitos cognitivos ou epistemológicos, essas tendências apresentariam uma vantagem prática, pois, da mesma maneira que uma criança não precisa aprender a digerir alimentos, fazendo-o corretamente de um modo automático, uma criança também não precisa aprender a elaborar uma gramática, tendo por base uma exposição a poucos e pobres inputs. Por uma questão de sobrevivência, nós todos chegamos naturalmente a dominar as regras de uma linguagem, convencidos de que os demais seguem as mesmas regras (p. 227-228).

Uma vez sumariamente reconstruídas e expostas as objeções de Nagel, procedamos agora a uma tentativa de resposta para elas.

Com relação à primeira objeção feita por Nagel a Chomsky, deve-se notar que o que o último entende por "adequação explanatória" de uma teoria linguística envolve como um elemento absolutamente indispensável 
o reconhecimento da correção da teoria por parte do falante, ou seja, o reconhecimento da correção e adequação dos princípios ou regras a ele apresentados pelo linguista relativamente às suas intuições de falante nativo (CHOM SKY, 1965, p. 19-20).

Com efeito, esse é justamente um dos aspectos em que a linguística proposta por Chomsky marca nitidamente sua distinção frente à linguística de corpus. De fato, os estruturalistas se debruçavam sobre um corpus de proferimentos de línguas nativas indígenas, como algo que Ihes era desconhecido, visando a explicitar as regras que estariam na sua base, mediante um procedimento de generalização indutiva. Nesse processo de descobrimento das regras, o próprio falante nativo não era consultado, i. e., suas intuições linguísticas não eram levadas em conta. A intervenção do falante só acontecia no momento do fornecimento dos dados a serem estudados, ou seja, do proferimento de sentenças que constituíam o corpus. Em suma, metodologicamente, a linguística proposta por Chomsky busca vir ao encontro das exigências do internalismo.

Com relação à segunda objeção, o que Nagel dá a entender é que Chomsky não pôde dar conta da justificação última das regras inatas que supostamente constituem a capacidade geral de aprender as regras de uma língua natural particular, já que, de acordo com Nagel, em última análise, 0 máximo que Chomsky teria podido mostrar é que haveria nos aprendizes de uma língua uma tendência ou propensão natural a formar certas crenças sobre as regras de uma língua natural, crença essa que obteria sua confirmação pela sua conformidade com o comportamento linguístico geral. Quer dizer, a "justificação" seria dada, no fim das contas, pelo fenômeno da concordância humana, não uma concordância convencional, mas uma concordância fundada na natureza humana, que seria a base última de toda justificação tomada nos moldes do segundo Wittgenstein.

Entretanto, Chomsky não aceitaria essa interpretação, tendo em vista que as regras que constituem a capacidade de aprender uma língua não são descobertas como algo que leva contingentemente a um acordo ou conformidade geral. Pelo contrário, Chomsky fornece uma justificação a priori dessas regras, porque elas definem, com validade universal, todas as possibilidades combinatórias sintáticas, frente às quais qualquer língua natural humana particular tem de se constituir como uma seleção determinada de tais combinações.

Desse modo, Chomsky rejeitaria a interpretação feita por Nagel (1974, p. 226), quando este afirma "que a tendência inata universal de chegar a determinadas regras é suficiente, no caso da linguagem, para assegurar a correção das intuições de um falante individual. Mas cada indivíduo precisa 
ainda saber que ele está em conformidade com a tendência universal [...]. E isso é uma questão que está aberta à investigação empírica". Em contraposição a isso, segundo Chomsky, o indivíduo pode saber a priori que suas intuições estarão em conformidade às dos demais, não porque "haja uma tendência inata e natural a supor que os outros vão interpretar as regras da gramática do mesmo modo que ele", mas porque é possível saber a priori para onde a tendência geral vai convergir, pois há um framew ork de regras estabelecido a priori, que torna necessária essa interpretação.

GLENDAY, Candice. Chomsky and the cartesian linguistics. Trans/Form/Ação, (São PauIo); v.33(1), 2010, p.183-202.

A BSTRACT: This paper intends to present and critically examine some of the main arguments provided
by the N orth-A merican linguist N oam Chomsky to support the thesis of an innate origin of a universal
grammar, which is commonly associated with the rationalist philosophical tradition, as the only possible
explanation of the specific features of human language and its acquisition around early childhood.
Some criticisms made by Thomas Nagel on Chomsky's so-called biological innatism will be then
examined, and at the end of the paper we shall defend Chomsky's arguments in favor of his innatism.

KE YWO RDS: biological innatism, language, universal grammar, rationalism

\section{Referências}

CHOMSKY, N. Aspects of the theory of syntax. Cambridge: The MIT Press, 1965.

. The minimalist program. Cambridge: The MIT Press, 1995.

. Cartesian linguistics: a chapter in the history of rationalist thought. Edited by J ames McGilvray. 2 th ed. New Zealand: Cybereditions, 2002.

DUMMETT, M. What do I know when I know a language. In: LECTURE HELD AT THE CENTENARY CELEBRATIONS OF THE STOCKHOLM UNIVERSITY, May 24, 1978. p. 1-15.

KANT, I. Crítica da razão pura. Tradução de Valério Rohden e Udo Moosburger. São Paulo: A bril, 1983. (Os Pensadores).

LEIBNIZ, G. W. Neue Abhandlungen über den menschlichen Verstand. Frankfurt am Main: Suhrkamp, 1996. v. 1, edição bilingüe francês/alemão,

LYONS, J. Chomsky. London: Fontana, 1975. Título original, 1970.

M ARQUES, U. R. A. Sobre o 'Inato' em Kant. Analytica, v. 12, n. 2, 2008. Disponível em: < http://www.analytica.inf.br> . Acesso em: jan. 2010. 
NAGEL, T. Linguistics and epistemology. In: HARMAN, Gilbert (Ed.). On Noam Chomsky: critical essays. New York: Anchor Press, 1974. p. 219-228.

ROBINS, R. H. Pequena história da lingüística. Tradução de Luiz Martins Monteiro. Rio de J aneiro: A o Livro Técnico, 1979.

STEGMÜLLER, W. A filosofia contemporânea. São Paulo: EPU, 1976. v. 2.

WITTGENSTEIN, L. Investigações filosóficas. Tradução de J osé Carlos Bruni. São Paulo: A bril Cultural, 1975. . The blue and brown Books. Oxford: Basil Blackwell, 1987. 